\title{
Maternal urinary manganese and risk of low birth weight: a case-control study
}

Wei Xia ${ }^{{ }^{*}}$, Yanqiu Zhou ${ }^{1 \dagger}$, Tongzhang Zheng ${ }^{2}$, Bin Zhang ${ }^{3}$, Bryan A. Bassig ${ }^{4}$, Yuanyuan Li', John Pierce Wise Sr. ${ }^{5}$, Aifen Zhou ${ }^{3}$, Yanjian Wan', Youjie Wang ${ }^{1}$, Chao Xiong ${ }^{1,3}$, Jinzhu Zhao ${ }^{3}$, Zhengkuan Li ${ }^{6}$, Yuanxiang Yao ${ }^{7}$, Jie Hu', Xinyun $\operatorname{Pan}^{1}$ and Shunqing $\mathrm{Xu}{ }^{1 *}$

\begin{abstract}
Background: Manganese $(\mathrm{Mn})$ is an essential element for humans, but exposure to high levels has been associated with adverse developmental outcomes. Early epidemiological studies evaluating the effect of $\mathrm{Mn}$ on fetal growth are inconsistent.

Methods: We investigated the association between maternal urinary Mn during pregnancy and the risk of low birth weight (LBW). Mn concentrations in maternal urine samples collected before delivery were measured in 816 subjects (204 LBW cases and 612 matched controls) recruited between 2012 and 2014 in Hubei Province, China.

Results: The median Mn concentration in maternal urine was $0.69 \mu \mathrm{g} / \mathrm{g}$ creatinine. Compared to the medium tertile of Mn levels, an increased risk of LBW was observed for the lowest tertile ( $\leq 0.30 \mu \mathrm{g} / \mathrm{g}$ creatinine) [adjusted odds ratio $(\mathrm{OR})=1.28 ; 95 \%$ confidence interval $(\mathrm{Cl})=0.67,2.45]$, and a significantly increased risk of LBW was observed for the highest tertile ( $\geq 1.16 \mu \mathrm{g} / \mathrm{g}$ creatinine) [adjusted $\mathrm{OR}=2.04 ; 95 \% \mathrm{Cl}=1.12,3.72$ ]. A curvilinear relationship between maternal urinary $\mathrm{Mn}$ and risk of LBW was observed, showing that the concentration at $0.43 \mu \mathrm{g} / \mathrm{g}$ creatinine was the point of inflection. Similar associations were observed among the mothers with female infants and among the younger mothers $<28$ years old. However, among the mothers with male infants or the older mothers $\geq 28$ years old, only higher levels of Mn were positively associated with LBW.

Conclusions: Lower or higher levels of maternal urinary Mn are associated with LBW, though only the association of LBW risk and higher levels of Mn was statistically significant. The findings also show that the associations may vary by maternal age and infant sex, but require confirmation in other populations.
\end{abstract}

Keywords: Manganese, Low birth weight, Maternal urine, Fetal

\section{Background}

Low birth weight (LBW), a birth weight less than $2,500 \mathrm{~g}$, constitutes a significant public health problem in both developing and developed countries. The estimated 30 million LBW infants born annually ( $23.8 \%$ of all births) worldwide often face severe short- and longterm health consequences [1]. LBW is not only a major determinant of mortality, morbidity and disability in

\footnotetext{
*Correspondence: xiawei@hust.edu.cn; xust@hust.edu.cn

${ }^{\dagger}$ Equal contributors

${ }^{1}$ Key Laboratory of Environment and Health (HUST), Ministry of Education \& Ministry of Environmental Protection, and State Key Laboratory of Environmental Health (Incubation), school of Public Health, Tongji Medical College, Huazhong University of Science and Technology, Wuhan, Hubei, People's Republic of China

Full list of author information is available at the end of the article
}

infancy and childhood [2], but is also associated with a number of health problems in later life, such as neurodevelopmental disabilities, growth and metabolic disorders, and respiratory disorders [3]. There are growing concerns about the role of environmental exposures in the etiology of LBW.

Manganese (Mn) poses a particular challenge in that it is an essential nutrient for normal development, with involvement in bone formation, protein and energy metabolism, and metabolic regulation, but it is also a potential toxicant if overexposure occurs [4]. Mn occurs naturally in the environment and has several industrial uses including production of steels, portable batteries, and aluminum beverage cans. The general population is exposed to Mn through consumption of food and water, 
inhalation of air, and contact with consumer products that contain Mn. Human activities such as mining, metal smelting, and other industrial uses of Mn may increase Mn levels in the environment [5]. An increasing number of studies suggest that excess exposure to Mn may have detrimental effects on the developing organism, particularly neurological development $[6,7]$. Also, maternal exposure to high levels of $\mathrm{Mn}$ through drinking water in Bangladesh has been related to increased fetal abnormalities and fetal mortality [8].

Unlike other toxic metals like lead, which have no beneficial use in the human body, the effects of $\mathrm{Mn}$ on fetal growth are likely to be more complex because it is both an essential nutrient and a potential toxicant, depending on the amount of exposure. Findings from studies evaluating prenatal exposure to $\mathrm{Mn}$ and birth size have been inconsistent. Maternal exposure to elevated levels of Mn in water has been associated with a reduction in birth weight [9]. However, some studies evaluating birth weight and maternal blood $\mathrm{Mn}$ levels have observed no such association [10,11], and a previous study indicated that lower maternal blood Mn levels were associated with intrauterine growth retardation [12]. A recent study evaluated the association in 470 mother-infant pairs and found that both lower and higher maternal blood $\mathrm{Mn}$ concentrations were associated with decreased birth weight [13]. Some other studies subsequently reported similar results and suggested that there may be a parabolic dose-response relationship between maternal blood $\mathrm{Mn}$ concentrations and birth weight [14-16].

These studies on Mn exposure and infant birth weight were limited to only include normal birth weight infants or included only a few LBW infants in their study populations and therefore couldn't estimate the risk for LBW. With the high rate of industrial development and urban expansion in China, elevated levels of $\mathrm{Mn}$ in air and soil have been reported in some areas $[17,18]$, which necessitates further study of the potential effects of this element on the developing fetus. Given this background, we conducted a nested case-control study that included 204 LBW cases and 612 matched controls in Hubei Province, China. Assessment of Mn exposure levels in pregnant women can be as a surrogate of exposure to the unborn child, because $\mathrm{Mn}$ can cross the placenta and transfer from the mother to the fetus [19]. Noninvasive urine based analysis is a traditional approach for evaluating trace-elements levels in the human body. Several studies conducted worldwide used $\mathrm{Mn}$ in urine to indicate occupational or environmental exposure for assessing health risks [20-22], and found associations between urinary Mn levels and adverse health outcomes $[20,23,24]$. In the present study, we examined the association between maternal urinary $\mathrm{Mn}$ concentrations and the risk of LBW. Potential effect modification by maternal age and infant sex, which has not been previously evaluated, was also examined.

\section{Methods \\ Study population}

The subjects in this study were participants in the prospective Healthy Baby Cohort (HBC) study. This study was conducted at three major maternity hospitals in Wuhan, Ezhou, and Macheng cities, which are located in Hubei province, in the central of People's Republic of China. Between November 2012 and April 2014, 16,293 women who gave birth at any of the three hospitals were recruited, and the participation rate was $78.7 \%$. Participant mothers received a detailed explanation of the study procedures and provided written informed consent at enrollment. The research protocol was approved by the ethical committee of Tongji Medical College, Huazhong University of Science and Technology, and the three study hospitals.

In this study, cases were mothers who delivered a singleton live infant with a birth weight $<2,500$ g. Controls were mothers who delivered a singleton live infant with normal birth weight between $\geq 2,500 \mathrm{~g}$ and $<$ 4,000 g. Potential cases and controls were excluded if they gave birth to multiple infants, a stillborn infant, or an infant with a birth defect. Women who did not have urine samples available for analysis were also excluded. For each case selected, three consecutive individual controls were randomly selected and matched to one case by delivery hospital, infant sex, and maternal age at conception (within 1-year interval). If more suitable matched controls were available for one case, only the top three with the closest maternal age to the case were selected. A total of 204 cases and 612 matched controls were included in the analysis.

\section{Data collection}

Women were interviewed after delivery by specially trained nurses in the three hospitals. The questionnaire collected information regarding demographic factors, household income, education, smoking behavior, and alcohol consumption. Information on birth outcomes, reproductive history, disease, and pregnancy complications were abstracted from the medical records. The pre-pregnancy body mass index (BMI) of mothers was calculated using the self-reported weight before pregnancy and height, which was measured using a stadiometer. Gestational age was calculated by subtracting the date for the last menstrual period from the date of delivery. Infant birth weight was measured by delivery room staff using standardized anthropometric procedures. 


\section{Urinary Mn measurements}

The maternal urine samples were obtained during the hospital admission for delivery, and were collected in polypropylene tubes and stored at $-20{ }^{\circ} \mathrm{C}$ prior to analysis. All samples were coded and analyzed by lab personnel blind to their origin. Urine samples were thawed at room temperature before analysis, and $1 \mathrm{~mL}$ of urine from the supernatant was introduced in a Kirgen polypropylene conical centrifuge tubes. Then, $3 \% \mathrm{HNO}_{3}$ was added to the final volume of $5 \mathrm{~mL}$ for overnight nitrification. The resulting sample was digested by ultrasound at $40{ }^{\circ} \mathrm{C}$ for $1 \mathrm{~h}$ and then analyzed using inductively coupled plasma mass spectrometry (Agilent 7700, Agilent Technologies, Santa Clara, CA, USA). The standard Reference Material Human Urine (SRM2670a, National Institute of Standards and Technology, Gaithersburg, MD, USA) was used as an external quality control, and sample spike-recoveries were used to confirm analytical recovery, which was $95 \%$. A $3 \% \mathrm{HNO}_{3}$ blank was processed in each batch of samples to control for possible contamination. The samples were analyzed with an external calibration method, using eight standard concentrations ranging from 0 to $500 \mu \mathrm{g} / \mathrm{L}$. The limit of detection (LOD) for $\mathrm{Mn}$ in urine was $0.05 \mu \mathrm{g} / \mathrm{L}$. Field blanks were also included for quality control and the levels of $\mathrm{Mn}$ in the field blanks were $<$ LOD. The urine samples below the LOD were given a value one-half the LOD. Lead, arsenic, cadmium, and thallium were also measured simultaneously because previous studies have suggested that these metals are potentially associated with decreasing birth weight [25-28].

Urinary creatinine concentrations were measured using a commercially available diagnostic enzyme method (Mindray BS-200 CREA Kit, Shenzhen Mindray Biomedical Electronics CO., LTD., Shenzhen, China). Urine creatinine was used to adjust the urinary Mn concentrations $(\mu \mathrm{g} / \mathrm{L})$ in order to correct for urine dilution, and $\mathrm{Mn}$ concentrations were expressed as $\mu \mathrm{g} / \mathrm{g}$ creatinine.

\section{Statistical analysis}

The Wilcoxon signed rank test was used to compare distributions of Mn levels between cases and controls, because the distribution of maternal urinary Mn was skewed to the right. Conditional logistic regression analyses were performed to assess the association between maternal urinary $\mathrm{Mn}$ concentrations and risk of LBW. Maternal urinary Mn levels were analyzed as categorical variables based on the tertile distribution of Mn concentrations in the controls. Crude and adjusted odds ratios (ORs) and their $95 \%$ confidence intervals (CIs) were estimated comparing the lowest and highest tertile of Mn levels to the medium tertile. Household income was used to represent socioeconomic status in this study, because adjustment for income had a larger impact on the estimate than education. Inclusion of the two variables together in the adjusted model did not produce significantly different results compared to the addition of each individual variable into the model separately. In the final model, we adjusted for gestational age ( $<37$ weeks, $\geq 37$ weeks), household income $(\geq 50,000$, < 50,000 yuan per year), gestational hypertension (No, Yes), pre-pregnancy body mass index (<18.5, 18.5-23.9, $\geq 24$ ), parity (primiparous, multiparous), and passive smoking (No, Yes). Additional adjustment for occupational status, diabetes, and multivitamin supplement use during pregnancy did not result in material changes in the observed associations and thus were not included in the final models. Several metals that have been previously suggested to be associated with birth weight (lead, arsenic, cadmium, and thallium) were also adjusted for in the models to control for potential confounding, but inclusion of these metal variables either individually or together did not cause a significant change in the risk estimates associated with maternal urinary Mn concentrations. Smoking and alcohol consumption during pregnancy were not included because very few Chinese women smoke and drink throughout life. Risk estimates were stratified by infant sex and maternal age, and heterogeneity of effects by infant sex and maternal age were assessed by the Breslow-Day test. In addition, we applied the SAS macro LGTPHCURV8 [29] to fit restricted cubic splines to conditional logistic model to examine the possible non-linear relationship between maternal urinary Mn concentrations and risk of LBW. Maternal urinary $\mathrm{Mn}$ was regarded as a continuous variable, and the referent value was set to the median. The output showed the significance level from the likelihood ratio tests for non-linearity or linearity, and the results of spline or linear model were plotted. A two-sided $P$ value of $<0.05$ was considered statistically significant. All data analyses were performed using SAS (version 9.3; SAS Institute Inc., Cary, NC, USA).

\section{Results}

General characteristics of the cases and controls are presented in Table 1. Of the newborn infants, $49.5 \%$ were male. The mean maternal age at delivery was $28.1 \pm 4.7$ years with a range of 17 to 42 years. Compared to the controls, the case mothers were more likely to have fewer years of education, have a lower pre-pregnancy body mass index, and report a lower household income. There were higher proportions of case mothers who had gestational hypertension. Only one mother reported smoking and only three mothers reported drinking alcohol during their pregnancy.

The median Mn concentration in maternal urine was $0.69 \mu \mathrm{g} / \mathrm{g}$ creatinine (Additional file 1: Table S1). The LBW case mothers had significantly higher urinary Mn 
Table 1 Basic characteristics of low birth weight cases and controls [n (\%)]

\begin{tabular}{|c|c|c|c|c|c|}
\hline Characteristics & Cases $(n=204)$ & Controls $(n=612)$ & Alcohol use during pregnancy & & \\
\hline Infant sex & & & Yes & $2(1.0)$ & $1(3.3)$ \\
\hline Male & $101(49.5)$ & 303 (49.5) & No & $196(96.1)$ & $594(97.1)$ \\
\hline Female & $103(50.5)$ & 309 (50.5) & Missing & $6(2.9)$ & $17(2.8)$ \\
\hline
\end{tabular}

$<25$ years

25-29 years

$48(23.5)$

$146(23.8)$

$\geq 30$ years

$81(39.7)$

$75(36.7)$

$242(39.5)$

$224(36.6)$

Education

$\leq 9$ years

89 (43.6)

$167(27.3)$

9-12 years

$38(18.6)$

$>12$ years

$77(37.8)$

Missing

Household income

$<50,000$ yuan per year

$116(56.9)$

$61(29.9)$

$\geq 50,000$ yuan per year

$27(13.2)$

$159(77.9)$

$501(81.9)$

Primiparous

$45(22.1)$

$111(18.1)$

Gestational hypertension

Yes
No
Missing
Gestational diabetes
Yes

\section{$20(9.8)$}

$12(2.0)$

$183(89.7)$

$1(0.5)$

$598(97.7)$

$2(0.3)$

\section{7 (3.4)}

$197(96.6)$

$27(4.4)$

Pre-pregnancy BMI

$\begin{array}{lll}<18.5 \mathrm{~kg} / \mathrm{m}^{2} & 60(29.4) & 125(20.4) \\ 18.5-23.9 \mathrm{~kg} / \mathrm{m}^{2} & 108(52.9) & 385(62.9) \\ \geq 24 \mathrm{~kg} / \mathrm{m}^{2} & 26(12.8) & 85(13.9) \\ \text { Missing } & 10(4.9) & 17(2.8)\end{array}$

Multivitamin supplement during pregnancy

$\begin{array}{lll}\text { Yes } & 137(67.2) & 409(66.8) \\ \text { No } & 59(28.9) & 190(31.1) \\ \text { Missing } & 8(3.9) & 13(2.1) \\ \text { Smoking during pregnancy } & & \\ \text { No } & 198(97.1) & 608(99.4) \\ \text { Yes } & 1(0.5) & 0(0.0) \\ \text { Missing } & 5(2.4) & 4(0.6) \\ \text { Passive smoking during pregnancy } & \\ \text { Yes } & 47(23.0) & 129(21.1) \\ \text { No } & 149(73.0) & 464(75.8) \\ \text { Missing } & 8(3.9) & 19(3.1)\end{array}$

Table 1 Basic characteristics of low birth weight cases and controls [n (\%)] (Continued)

Alcohol use during pregnancy

levels compared to the control mothers (median: 1.09 vs. $0.64 \mu \mathrm{g} / \mathrm{g}$ creatinine, $P<0.01$ ). Older mothers $\geq 28$ years old had elevated Mn concentrations compared to younger mothers $<28$ years old among the controls (median: 0.67 vs. $0.59 \mu \mathrm{g} / \mathrm{g}$ creatinine) and the cases (median: 1.14 vs. $1.01 \mu \mathrm{g} / \mathrm{g}$ creatinine), although these differences were not statistically significant $(P>0.05)$. Further, $\mathrm{Mn}$ concentrations were somewhat higher in the mothers that gave birth to male infants compared to female infants among the controls (median: 0.68 vs. $0.59 \mu \mathrm{g} / \mathrm{g}$ creatinine, $P>0.05$ ) and the cases (median: 1.19 vs. $0.93 \mu \mathrm{g} / \mathrm{g}$ creatinine, $P>0.05$ ).

Table 2 shows the association between maternal urinary Mn levels and LBW risk. Compared to the medium tertile of Mn concentration (0.30-1.16 $\mu \mathrm{g} / \mathrm{g}$ creatinine), both the lowest and highest tertiles of $\mathrm{Mn}$ were associated with increased risk of LBW in the adjusted analysis, although the association was only significant for the highest tertile [adjusted OR $=1.28$ (95 \% CI: 0.67, 2.45) for the lowest tertile; adjusted OR $=2.04$ (95\% CI: 1.12 , 3.72) for the highest tertile]. In the restricted spline model after adjusting for the potential confounders, we observed a U-shaped relationship with a concentration at $0.43 \mu \mathrm{g} / \mathrm{g}$ creatinine as the point of inflection between maternal urinary Mn and risk of LBW (Fig. 1). However, the non-linear relationship was not significant $(P=0.12)$.

Results for stratified analyses by maternal age $(<28$ and $\geq 28$ years) and infant sex are shown in Table 3 and Table 4 , respectively. Among younger mothers ( $<28$ years), both lower and higher Mn concentrations in urine were associated with increased risk of delivering LBW infants, and the association was significant for the highest tertile [adjusted $\mathrm{OR}=1.88(95 \% \mathrm{CI}=0.74,4.80)$ for the lowest

Table 2 Risk of low birth weight associated with levels of manganese in maternal urine

\begin{tabular}{lllll}
\hline $\begin{array}{l}\text { Manganese } \\
(\mu \mathrm{g} / \mathrm{g} \text { creatinine })\end{array}$ & Cases & Controls & $\mathrm{OR}^{\mathrm{a}}(95 \% \mathrm{Cl})$ & $\mathrm{OR}^{\mathrm{b}}(95 \% \mathrm{Cl})$ \\
$\begin{array}{c}\text { Total }(n=816) \\
<0.30\end{array}$ & 55 & 204 & $1.11(0.71,1.74)$ & $1.28(0.67,2.45)$ \\
$0.30-1.16$ & 48 & 204 & 1.00 & 1.00 \\
$\geq 1.16$ & 101 & 204 & $2.19(1.46,3.27)$ & $2.04(1.12,3.72)$ \\
\hline
\end{tabular}

Abbreviation: $O R$ odds ratio; $\mathrm{Cl}$ confidential interval

a Unadjusted odds ratio

${ }^{\mathrm{b}}$ Adjusted for gestational age, household income, pre-pregnancy body mass index, parity, passive smoking, gestational hypertension 


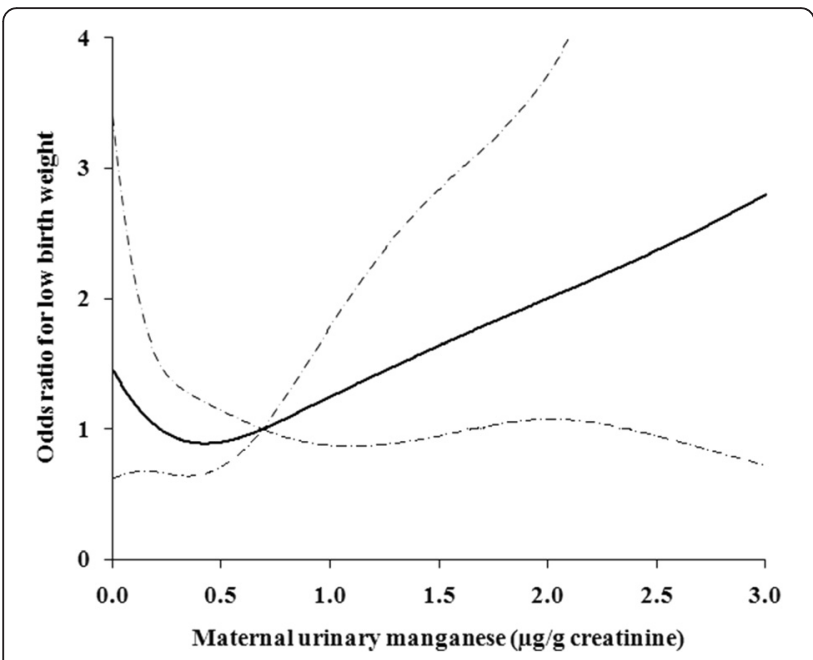

Fig. 1 The relationship between maternal urinary manganese concentration ( $\mu \mathrm{g} / \mathrm{g}$ creatinine) and risk of LBW, adjusted for gestational age, household income, pre-pregnancy body mass index, parity, passive smoking, and gestational hypertension. The risk estimate is indicated by the solid line, and the $95 \%$ confidence intervals are represented by the dashed lines

tertile; adjusted $\mathrm{OR}=2.74$ (95\% CI $=1.07$, 7.03) for the highest tertile]. Although no significant interaction between maternal age and maternal urinary Mn levels was observed $(P$ heterogeneity $=0.19)$, a positive association with LBW was only observed for the highest tertile among older mothers ( $\geq 28$ years) [adjusted OR $=1.98$ $(95 \% \mathrm{CI}=0.82,4.74)]$. For mothers that gave birth to female infants, lower and higher Mn levels were associated with increased risk of LBW compared to the medium tertile [adjusted $\mathrm{OR}=2.12$ (95 \% CI: 0.86, 5.25) for the lowest tertile; adjusted $\mathrm{OR}=1.94$ (95\% CI: $0.88,4.45)$ for the highest tertile], although the associations were not significant. For mothers that gave birth to male infants, a positive association with LBW was only observed for the highest tertile of $\mathrm{Mn}$ [adjusted $\mathrm{OR}=1.88$ (95 \% CI: 0.85, 4.79)]. Also, there was no statistical evidence of heterogeneity in risk according to infant sex $(P$ heterogeneity $=0.24)$. Moreover, we obtained consistent results with the restricted spline models, showing that a non-linear risk pattern in younger mothers and mothers who gave birth to female infants (Additional file 1: Figure S1), though the non-linear relationship was only significant in mothers who gave birth to female infants $(P=0.82$ and $P=0.02$, respectively). For older mothers and mothers who gave birth to male infants, we observed a possible linear trend between maternal urinary Mn concentrations and risk of LBW $(P=0.03$ and $P=0.08$, respectively).

\section{Discussion}

In this nested case-control study, we observed an increased risk of LBW for maternal urinary Mn levels in the lowest tertile and highest tertile, though the associations with LBW risk were only significant for higher levels of urinary Mn. These associations were observed even after adjustment for known and suspected risk factors for LBW. We further identified a curvilinear relationship between maternal urinary Mn level and risk of LBW, which was apparent in female infants. The observed relationship was consistent with our a priori hypothesis, and supports the idea that Mn may contribute to adverse birth outcomes at both low and high exposure levels.

The number of studies on biomarkers of $\mathrm{Mn}$ has been increased during recent two decades, but the results on the representative biomarkers of $\mathrm{Mn}$ are contradictory, including $\mathrm{Mn}$ in urine, blood and hair. Some studies showed that urinary Mn may have limited use for occupational population as a direct measure of $\mathrm{Mn}$ exposure due to high variability within person over time $[30,31]$. However, previous studies also have shown that $\mathrm{Mn}$ detected in spot urine sample is able to correctly classify individuals into the higher levels of Mn vs. the lower levels of Mn exposure [20, 21]. Since behavior, consumption habits, and ambient living environment of individuals' do not change easily, we used urinary $\mathrm{Mn}$ concentration to divide the study populations into three levels of exposure to investigate its association with risk of LBW. Also, elevated urinary concentrations have been reported to correlate to elevated concentrations of $\mathrm{Mn}$ in drinking water in pregnant women living in Bangladeshi,

Table 3 Risk of low birth weight associated with maternal urinary manganese levels, stratified by maternal age

\begin{tabular}{|c|c|c|c|c|c|c|c|}
\hline \multirow{2}{*}{$\begin{array}{l}\text { Manganese } \\
\text { levels }^{\mathrm{a}}\end{array}$} & \multicolumn{3}{|c|}{ Age $<28$ years old $(n=392)$} & \multicolumn{3}{|c|}{ Age $\geq 28$ years old $(n=424)$} & \multirow{2}{*}{$\begin{array}{l}P \text { for } \\
\text { heterogeneity }\end{array}$} \\
\hline & $\overline{\mathrm{Ca} / \mathrm{Co}}$ & $\mathrm{OR}^{\mathrm{b}}(95 \% \mathrm{Cl})$ & $\mathrm{OR}^{\mathrm{C}}(95 \% \mathrm{Cl})$ & $\overline{\mathrm{Ca} / \mathrm{Co}}$ & $\mathrm{OR}^{\mathrm{b}}(95 \% \mathrm{Cl})$ & $\mathrm{OR}^{\mathrm{C}}(95 \% \mathrm{Cl})$ & \\
\hline Tertile 1 & $31 / 98$ & $1.80(0.91,3.56)$ & $1.88(0.74,4.80)$ & $23 / 106$ & $0.72(0.39,1.34)$ & $0.84(0.31,2.24)$ & 0.19 \\
\hline Tertile 2 & $17 / 98$ & 1.00 & 1.00 & $31 / 106$ & 1.00 & 1.00 & \\
\hline Tertile 3 & $50 / 98$ & $3.14(1.67,5.92)$ & $2.74(1.07,7.03)$ & $52 / 106$ & $1.69(0.98,2.90)$ & $1.98(0.82,4.74)$ & \\
\hline
\end{tabular}

Abbreviations: $\mathrm{ca} / \mathrm{co}$, numbers of cases and controls; $\mathrm{Cl}$ confidence interval; OR odds ratio

${ }^{a}$ Manganese levels ( $\mu \mathrm{g} / \mathrm{g}$ creatinine): age $<28$ years, tertile $1(<0.30)$, tertile $2(0.30-1.08)$, tertile $3(\geq 1.09)$; age $\geq 28$ years, tertile $1(<0.28)$, tertile $2(0.28-1.21)$, tertile $3(\geq 1.22)$

${ }^{b}$ Crude odds ratio

c Adjusted for gestational age, household income, pre-pregnancy body mass index, parity, passive smoking, and gestational hypertension 
Table 4 Risk of low birth weight associated with maternal urinary manganese levels, stratified by infant sex

\begin{tabular}{|c|c|c|c|c|c|c|c|}
\hline \multirow{2}{*}{$\begin{array}{l}\text { Manganese } \\
\text { levels }^{\mathrm{a}}\end{array}$} & \multicolumn{3}{|c|}{ Male $(n=404)$} & \multicolumn{3}{|c|}{ Female $(n=412)$} & \multirow{2}{*}{$\begin{array}{l}P \text { for } \\
\text { heterogeneit) }\end{array}$} \\
\hline & $\mathrm{Ca} / \mathrm{Co}$ & $\mathrm{OR}^{\mathrm{b}}(95 \% \mathrm{Cl})$ & $\mathrm{OR}^{\mathrm{C}}(95 \% \mathrm{Cl})$ & $\overline{\mathrm{Ca} / \mathrm{Co}}$ & $\mathrm{OR}^{\mathrm{b}}(95 \% \mathrm{Cl})$ & $\mathrm{OR}^{\mathrm{C}}(95 \% \mathrm{Cl})$ & \\
\hline Tertile 1 & $22 / 101$ & $0.73(0.38,1.40)$ & $0.64(0.22,1.83)$ & $32 / 103$ & $1.55(0.81,2.98)$ & $2.12(0.86,5.25)$ & 0.24 \\
\hline Tertile 2 & 29/101 & 1.00 & 1.00 & 20/103 & 1.00 & 1.00 & \\
\hline Tertile 3 & $50 / 101$ & $1.77(1.02,3.06)$ & $1.88(0.85,4.79)$ & $51 / 103$ & $2.65(1.46,4.80)$ & $1.94(0.88,4.45)$ & \\
\hline
\end{tabular}

Abbreviations: $\mathrm{ca} / \mathrm{co}$, numbers of cases and controls; $\mathrm{Cl}$ confidence interval; OR odds ratio

${ }^{a}$ Manganese levels $(\mu \mathrm{g} / \mathrm{g}$ creatinine): male, tertile $1(<0.31)$, tertile $2(0.31-1.24)$, tertile $3(\geq 1.25)$; female, tertile $1(<0.28)$, tertile $2(0.28-1.04)$, tertile $3(\geq 1.05)$

${ }^{b}$ Crude odds ratio

c Adjusted for gestational age, household income, pre-pregnancy body mass index, parity, passive smoking, and gestational hypertension

suggesting maternal urine may serve as a useful Mn biomarker to estimate prenatal exposure [22].

In the present study, none of our study participants had a urinary Mn level higher than the upper limit of normal urinary $\mathrm{Mn}$ values for adults $(10 \mu \mathrm{g} / \mathrm{L})$ [32]. Table 5 shows the comparison of Mn concentrations in urine from this study and previous studies in pregnant women and general population around the world. The results showed that the Mn concentrations in maternal urine observed in this study (median $0.38 \mu \mathrm{g} / \mathrm{L}, 0.69 \mu \mathrm{g} /$ $\mathrm{g}$ creatinine) were comparable to those seen in pregnant women in western Australia (median $0.33 \mu \mathrm{g} / \mathrm{L}, 0.53 \mu \mathrm{g} /$ g creatinine) [33] and California, USA $(0.40 \mu \mathrm{g} / \mathrm{L})$ [34]. Compared to the pregnant women living in rural Bangladesh with higher $\mathrm{Mn}$ concentrations in drinking water than other places (median $1.60 \mu \mathrm{g} / \mathrm{L}$ ) [22], our study population had much lower urinary Mn concentrations. Previous studies have shown maternal blood Mn levels were increased during pregnancy $[10,35,36]$. The increase in Mn levels during pregnancy may be related to physiological factors, including increased intestinal absorption or tissue Mn mobilization [37, 38], reflecting increased need from the fetal development. Takser et al. [10] reported that blood Mn concentration in pregnant women at delivery was higher than nonpregnant women of reproductive age. In consistent with the findings, $\mathrm{Mn}$ concentrations in urine of pregnant women in this study were a little higher than those observed in the healthy women from Canada (median $0.09 \mu \mathrm{g} / \mathrm{L}$ ) [39], Japan (median $0.16 \mu \mathrm{g} / \mathrm{L}, 0.13 \mu \mathrm{g} / \mathrm{g}$ creatinine) [40], as well as the general population (including men and women) in France (median $0.31 \mu \mathrm{g} / \mathrm{L}$ ) [41] and Germany (arithmetic mean $0.09 \mu \mathrm{g} / \mathrm{L}$ ) [42].

Currently, there are no recommended values or guidelines for ideal urinary or blood Mn levels during pregnancy. In this study, we used the medium tertile of urinary $\mathrm{Mn}$ as the reference group, and observed that both the lowest and highest tertile were positively associated with LBW. One explanation for the weaker association between the lowest tertile of $\mathrm{Mn}$ and LBW risk might be that the prevalence of Mn deficiency is low in our population. In a previous study, Eum et al. [15] assessed the relationship between maternal blood $\mathrm{Mn}$ levels before delivery and birth weight categorized as a

Table 5 Comparison of manganese concentrations in urine from the present study and previous studies

\begin{tabular}{|c|c|c|c|c|c|c|c|}
\hline & & & & & & Percentiles & \\
\hline Location & Author (year) & Population & Number & Arithmetic Mean & 25th & 50th & 75th \\
\hline $\begin{array}{l}\text { Hubei, } \\
\text { China }\end{array}$ & $\begin{array}{l}\text { Present study } \\
(2014)\end{array}$ & $\begin{array}{l}\text { Pregnant } \\
\text { women }\end{array}$ & 816 & $\begin{array}{l}0.66 \mu \mathrm{g} / \mathrm{L} 1.12 \mu \mathrm{g} / \mathrm{g} \\
\text { creatinine }\end{array}$ & $\begin{array}{l}0.13 \mu \mathrm{g} / \mathrm{L} 0.18 \mu \mathrm{g} / \mathrm{g} \\
\text { creatinine }\end{array}$ & $\begin{array}{l}0.38 \mu \mathrm{g} / \mathrm{L} 0.69 \mu \mathrm{g} / \mathrm{g} \\
\text { creatinine }\end{array}$ & $\begin{array}{l}0.85 \mu \mathrm{g} / \mathrm{L} 1.87 \mu \mathrm{g} / \mathrm{g} \\
\text { creatinine }\end{array}$ \\
\hline $\begin{array}{l}\text { Western } \\
\text { Australia }\end{array}$ & $\begin{array}{l}\text { Callan } \\
\text { (2013) [33] }\end{array}$ & $\begin{array}{l}\text { Pregnant } \\
\text { women }\end{array}$ & 173 & $\begin{array}{l}1.00 \mu \mathrm{g} / \mathrm{L} 1.22 \mu \mathrm{g} / \mathrm{g} \\
\text { creatinine }\end{array}$ & - & $\begin{array}{l}0.33 \mu \mathrm{g} / \mathrm{L} 0.53 \mu \mathrm{g} / \mathrm{g} \\
\text { creatinine }\end{array}$ & - \\
\hline California, USA & $\begin{array}{l}\text { Gunier } \\
\text { (2014) [34] }\end{array}$ & $\begin{array}{l}\text { Pregnant } \\
\text { women }\end{array}$ & 59 & - - & $0.20 \mu \mathrm{g} / \mathrm{L}$ & $0.40 \mu \mathrm{g} / \mathrm{L}$ & $0.60 \mu \mathrm{g} / \mathrm{L}$ \\
\hline Bangladeshi & $\begin{array}{l}\text { Ljung } \\
\text { (2009) [22] }\end{array}$ & $\begin{array}{l}\text { Pregnant } \\
\text { women }\end{array}$ & 388 & $2.50 \mu \mathrm{g} / \mathrm{L}$ & $0.90 \mu \mathrm{g} / \mathrm{L}$ & $1.60 \mu \mathrm{g} / \mathrm{L}$ & $2.80 \mu \mathrm{g} / \mathrm{L}$ \\
\hline Canada & $\begin{array}{l}\text { Health Canada } \\
\text { (2010) [39] }\end{array}$ & Women & 5309 & $0.15 \mu \mathrm{g} / \mathrm{L}$ & $<\mathrm{LOD}$ & $0.09 \mu \mathrm{g} / \mathrm{L}$ & $0.17 \mu \mathrm{g} / \mathrm{L}$ \\
\hline Japan & $\begin{array}{l}\text { Ohashi } \\
\text { (2006) [40] }\end{array}$ & Women & 1000 & - - & - - & $\begin{array}{l}0.16 \mu \mathrm{g} / \mathrm{L} 0.13 \mu \mathrm{g} / \mathrm{g} \\
\text { creatinine }\end{array}$ & - - \\
\hline France & $\begin{array}{l}\text { Goullé } \\
\text { (2005) [41] }\end{array}$ & $\begin{array}{l}\text { General } \\
\text { population }\end{array}$ & 100 & - - & - - & $0.31 \mu \mathrm{g} / \mathrm{L}$ & - - \\
\hline Germany & $\begin{array}{l}\text { Heitland } \\
\text { (2006) [42] }\end{array}$ & $\begin{array}{l}\text { General } \\
\text { population }\end{array}$ & 87 & $0.09 \mu \mathrm{g} / \mathrm{L}$ & - - & - - & - - \\
\hline
\end{tabular}


binary variable (below $3000 \mathrm{~g}$ or more than $3000 \mathrm{~g}$ ) in 331 full-term infants. They used the medium quintile as the reference group and found that the lowest $(<16.9 \mu \mathrm{g} / \mathrm{L})$ and the highest quintiles $(\geq 26.9 \mu \mathrm{g} / \mathrm{L})$ of blood Mn were associated with an increased risk of delivering infants with a birth weight below 3000 g. However, the associations were not significant for the lowest quintile (adjusted $\mathrm{OR}=2.77 ; 95 \% \mathrm{CI}$ : 0.89, 8.65) and the highest quintile of Mn levels (adjusted $\mathrm{OR}=2.66 ; 95 \% \mathrm{CI}: 0.84,8.08)$. Given that the risks observed in that study were in relation to birth weights $<3000 \mathrm{~g}$, it is possible that they didn't include LBW infants or only included a small number of LBW infants in the study.

Some previous studies also investigated the relationship between maternal Mn exposure and infant birth weight. Vigeh et al. [13] reported that intrauterine growth retardation was positively associated with maternal blood $\mathrm{Mn}$ and negatively associated with cord blood $\mathrm{Mn}$ in 271 mother-infant pairs from Tehran, Iran, but the study did not evaluate non-linear relationships. Zota et al. [13] found a non-linear relationship between maternal $\mathrm{Mn}$ blood Mn levles and birth weight in a cohort of 470 mother-infant pairs from Oklahoma. They reported an inverted U-shaped relationship between maternal blood Mn levels and birth weight with a concentration of $31 \mu \mathrm{g} / \mathrm{L}$ as the point of inflection. The report of Eum et al. [15] found a consistent result that the infant birth weight increased with maternal blood Mn concentration up to $35 \mu \mathrm{g} / \mathrm{L}$, and then decreased. Chen et al. [14] also obtained similar results in a study of 172 mother-infant pairs in Shanghai in that an inverted Ushaped relationship was found between maternal blood Mn levels and birth weight. A similar parabolic doseresponse relationship between cord blood Mn concentrations and birth weight was observed by Guan et al. [16] in Dalian City, northern China $(n=125)$. Interestingly, in consistent with the studies, we also found a potential $\mathrm{U}$-shaped relationship between maternal urinary Mn level and risk of LBW. However, the non-linear relationship may vary by maternal age and infant sex, and the nonlinear pattern was apparent in mothers who gave birth to female infants.

Infant sex is known to influence pregnancy outcomes, and female infants are usually at higher risk of LBW since male infants have consistently higher birth weight throughout gestation compared to female infants [43]. However, the relationship between maternal Mn levels and infant sex has not been studied before. We observed that the mothers who gave birth to male infants had slightly higher Mn concentrations compared to mothers who gave birth to female infants, which is one possible explanation for why only higher but not lower Mn levels were associated with LBW risk among male infants. In addition, maternal age has been regarded as a factor that can affect blood Mn levels [18, 44], and a previous study also reported that urinary Mn levels increased at advanced ages [40]. In our analyses stratified by maternal age, only higher Mn exposure levels were associated with LBW risk among older mothers, whereas for younger mothers both lower and higher Mn levels were associated with an elevated LBW risk. A reason for this difference might be that the older mothers had elevated Mn concentrations compared to younger mothers, though there was no significant difference. The potential differences in the effect of Mn exposure on LBW according to sex and maternal age observed in this study should be interpreted carefully due to the insufficient sample size, and further studies are needed to confirm the results.

With respect to maternal exposure to higher levels of Mn being associated with LBW, one biologically plausible mechanism could be oxidative stress caused by high levels of $\mathrm{Mn}$, leading to impairment of cellular function and growth [45]. Experimental studies on fetal development also showed that maternal exposure to high levels of $\mathrm{Mn}$ through oral administration resulted in a decrease in fetal weight and retardation of the development of the skeleton and internal organs [46]. There is also a concern that $\mathrm{Mn}$ deficiency may cause adverse effects on fetal growth, in that it is a critical component of the bone matrix and an important cofactor for enzymes necessary for bone metabolism [47]. In animals, the main features of Mn deficiency are skeletal malformation and impaired growth $[48,49]$. Dietary deficiency of Mn has been associated with abnormal glucose tolerance and perturbation of carbohydrate metabolism in animal studies [50], which could also contribute to fetal growth restriction. More research is needed to assess the effect of $\mathrm{Mn}$ exposure during pregnancy on subsequent child development.

One of the strengths of our study is that the nested case-control design provided the opportunity to include all of the LBW infants in the cohort, and the cases and controls were matched on potentially important factors in order to reduce the influence of confounding. The other strength of our study includes the availability of interview data and medical records from all participants, which allowed us to adjust for other potential risk factors for LBW.

The limitation of this study is that Mn levels were measured in maternal urine at one spot time, which may not accurately reflect maternal $\mathrm{Mn}$ load or fetal exposure during the entire pregnancy. Biliary excretion is the main pathway by which $\mathrm{Mn}$ is excreted with most of the element ultimately being excreted in the feces [51], and urinary Mn excretion representing about $5 \%$ of the total excreted amount [52]. Recent studies suggested that levels of Mn measured in tooth dentin, toenails or cord blood may constitute valid biomarkers of early life 
exposure [34, 53]. Future studies are needed that use these biomarkers to investigate Mn exposure and birth outcomes. In addition, repeated measures of erythrocytes $\mathrm{Mn}$ over trimesters may also provide an effective biomarker for $\mathrm{Mn}$ exposure during pregnancy [36]. A prospective study of $\mathrm{Mn}$ concentrations measured at different time points during pregnancy may help to evaluate how Mn levels change over the course of the pregnancy and whether there is a critical exposure window for the effect of Mn on fetal development.

\section{Conclusions}

Our nested case-control study found that both lower and higher levels of Mn concentration, as measured in maternal urine before delivery, was associated with increased risk of infant LBW. The associations were further observed to vary by maternal age and infant sex. This observation suggests that $\mathrm{Mn}$ levels during pregnancy may be important for fetal growth.

\section{Additional file}

Additional file 1: Distribution of maternal urianry manganese and restricted spline curves association between urinary manganese concentration and risk of low birth weigh in the stratified analysis. (DOCX $104 \mathrm{~kb})$

\section{Abbreviations}

LBW: Low birth weight; Mn: Manganese; Cl: Confidence interval; OR: Odds ratio; BMI: Body mass index; LOD: Limit of detection.

\section{Competing interests}

The authors have no conflict of interest to declare.

\section{Authors' contributions}

WX and $Y Z$ wrote the manuscript. BZ, YL, AZ, YW, ZL, YY, TZ, and SX contributed to the study design. $B Z, T Z$, and $S X$ developed the initial protocol. BB, JW, YW, and TZ reviewed and revised the manuscript. YZ, JH, and XP performed the Mn analyses. WX, CX, and JZ performed the statistical analyses. All authors reviewed and approved the manuscript.

\section{Acknowledgments}

This work was supported by the R\&D Special Fund for Public Welfare Industry (Environment) (201309048), the National Natural Science Foundation of China (21437002, 81372959, 81402649), and the National Basic Research Program of China (973 Program) (2012CB722401). Also, this work was partly supported by Fogarty training grants (D43TW 008323 and D43TW 007864-01) from the US National Institutes of Health.

\footnotetext{
Author details

${ }^{1}$ Key Laboratory of Environment and Health (HUST), Ministry of Education \& Ministry of Environmental Protection, and State Key Laboratory of Environmental Health (Incubation), school of Public Health, Tongji Medical College, Huazhong University of Science and Technology, Wuhan, Hubei, People's Republic of China. ${ }^{2}$ Department of Environmental Health Sciences, Brown School of Public Health, Providence, RI, USA. ${ }^{3}$ Women and Children Medical and Healthcare Center of Wuhan, Wuhan, Hubei, People's Republic of China. ${ }^{4}$ Department of Environmental Health Sciences, Yale School of Public Health, New Haven, CT, USA. ${ }^{5}$ Wise Laboratory of Environmental and Genetic Toxicology, Portland, ME, USA. ' $M a c h e n g$ Maternal and Child Health Care Hospital, Macheng, Hubei, People's Republic of China. ${ }^{7}$ Ezhou Maternal and Child Health Hospital, Ezhou, Hubei, People's Republic of China.
}

Received: 16 August 2015 Accepted: 3 February 2016

Published online: 12 February 2016

\section{References}

1. WHO. World Health Organization. Feto-maternal nutrition and low birth weight. http://www.who.int/nutrition/topics/feto_maternal/en/ Accessed 24 Dec 2015. 2005

2. Lawn JE, Cousens S, Zupan J. 4 million neonatal deaths: when? Where? Why? Lancet. 2005;365(9462):891-900.

3. Johnson RC, Schoeni RF. Early-life origins of adult disease: national longitudinal population-based study of the United States. Am J Public Health. 2011;101(12):2317-24

4. Crossgrove J, Zheng W. Manganese toxicity upon overexposure. NMR Biomed. 2004;17(8):544-53.

5. He ZL, Yang XE, Stoffella PJ. Trace elements in agroecosystems and impacts on the environment. J Trace Elem Med Bio. 2005;19(2-3):125-40.

6. Bouchard MF, Sauvé S, Barbeau B, Legrand M, Brodeur M-Ë, Bouffard T, et al. Intellectual impairment in school-age children exposed to manganese from drinking water. Envrion Health Perspect. 2011;119(1):138.

7. Menezes-Filho JA, Novaes CO, Moreira JC, Sarcinelli PN, Mergler D. Elevated manganese and cognitive performance in school-aged children and their mothers. Environ Res. 2011;111(1):156-63.

8. Hafeman D, Factor-Litvak P, Cheng Z, van Geen A, Ahsan H. Association between manganese exposure through drinking water and infant mortality in Bangladesh. Environ Health Perspect. 2007;115(7):1107-12.

9. Grazuleviciene R, Nadisauskiene R, Buinauskiene J, Grazulevicius T. Effects of elevated levels of manganese and iron in drinking water on birth outcomes. Pol J Envriron Stud. 2009:18(5):819-25.

10. Takser L, Lafond J, Bouchard M, St-Amour G, Mergler D. Manganese levels during pregnancy and at birth: relation to environmental factors and smoking in a Southwest Quebec population. Environ Res. 2004:95(2):119-25.

11. Mora AM, van Wendel de Joode B, Mergler D, Córdoba L, Cano C, Quesada $\mathrm{R}$, et al. Maternal blood and hair manganese concentrations, fetal growth, and length of gestation in the ISA cohort in Costa Rica. Environl Res. 2015;136:47-56.

12. Vigeh M, Yokoyama K, Ramezanzadeh F, Dahaghin M, Fakhriazad E, Seyedaghamiri $Z$, et al. Blood manganese concentrations and intrauterine growth restriction. Reprod Toxicol. 2008;25(2):219-23.

13. Zota AR, Ettinger AS, Bouchard M, Amarasiriwardena CJ, Schwartz J, Hu H, et al. Maternal blood manganese levels and infant birth weight. Epidemiology. 2009:20(3):367.

14. Chen L, Ding G, Gao Y, Wang P, Shi R, Huang H, et al. Manganese concentrations in maternal-infant blood and birth weight. Environ Sci Pollut R. 2014;21(9):6170-5.

15. Eum J-H, Cheong H-K, Ha E-H, Ha M, Kim Y, Hong Y-C, et al. Maternal blood manganese level and birth weight: a MOCEH birth cohort study. Environ Heal. 2014;13(1):31

16. Guan $\mathrm{H}$, Wang M, Li X, Piao F, Li Q, Xu L et al. Manganese concentrations in maternal and umbilical cord blood: related to birth size and environmental factors. Eur J Publlic health. 2013. DOl: http://dx.doi.org/10.1093/eurpub/ckt033.

17. Li M, Luo Y, Su Z. Heavy metal concentrations in soils and plant accumulation in a restored manganese mineland in Guangxi. South China Environ Pollut. 2007;147(1):168-75.

18. Audrey S, Takser L, André M, Martin S, Donna M, Geneviève S-A, et al. A comparative study of manganese and lead levels in human umbilical cords and maternal blood from two urban centers exposed to different gasoline additives. Sci Total Environ. 2002;290(1):157-64.

19. Krachler M, Rossipal E, Micetic-Turk D. Trace element transfer from the mother to the newborn - Investigations on triplets of colostrum, maternal and umbilical cord sera. Eur J Clin Nutr. 1999;53:486-94.

20. Hassani H, Golbabaei F, Shirkhanloo H, Doust MT. Relations of biomarkers of manganese exposure and neuropsychological effects among welders and ferroalloy smelters. Ind Health. 2015. doi: http://doi.org/10.2486/indhealth. 2014-0250.

21. Järvisalo J, Olkinuoral M, Kiilunen M, Kivistö H, Ristola P, Tossavainen A, et al. Urinary and blood manganese in occupationally nonexposed populations and in manual metal are welders of mild steel. Int Arch Occup Environ Health. 1992;63(7):495-501.

22. Ljung KS, Kippler MJ, Goessler W, Grandér GM, Nermell BM, Vahter ME. Maternal and early life exposure to manganese in rural Bangladesh. Environ Sci Technol. 2009;43(7):2595-601. 
23. Liu B, Feng W, Wang J, Li Y, Han X, Hu H, et al. Association of urinary metals levels with type 2 diabetes risk in coke oven workers. Environ Pollut. 2016;210:1-8.

24. Lucchini RG, Guazzetti S, Zoni S, Benedetti C, Fedrighi C, Peli M, et al. Neurofunctional dopaminergic impairment in elderly after lifetime exposure to manganese. Neurotoxicology. 2014;45:309-17.

25. Andrews KW, Savitz DA, Hertz-Picciotto I. Prenatal lead exposure in relation to gestational age and birth weight: a review of epidemiologic studies. Am J Ind Med. 1994;26(1):13-32.

26. Hopenhayn C, Ferreccio C, Browning SR, Huang B, Peralta C, Gibb H, et al. Arsenic exposure from drinking water and birth weight. Epidemiology. 2003;14(5):593-602.

27. Hu X, Zheng T, Cheng Y, Holfordb T, Linc S, Leaderer B, et al. Distributions of heavy metals in the maternal and cord blood and the association with infant birth weight in China. J Reprod Med. 2015;60(1-2):21-9.

28. Kippler M, Tofail F, Gardner R, Rahman A, Hamadani JD, Bottai M, et al. Maternal cadmium exposure during pregnancy and size at birth: a prospective cohort study. Environ Health Perspect. 2012;120(2):284-9.

29. Li RHE, Louie M, Chen L, Spiegelman D. The SAS LGTPHCURV8 Macro. Boston: Channing Laboratory; 2006.

30. Smith D, Gwiazda R, Bowler R, Roels H, Park R, Taicher C, et al. Biomarkers of Mn exposure in humans. Am J Ind Med. 2007;50(11):801-11.

31. Baker MG, Simpson CD, Sheppard L, Stover B, Morton J, Cocker J, et al. Variance components of short-term biomarkers of manganese exposure in an inception cohort of welding trainees. J Trace Elem Med Bio. 2015;29:123-9.

32. McClatchey KD. Clinical laboratory medicine. 2 nd ed. Philadelphia : Lippincott Williams \& Wilkins; 2002. p. 425

33. Callan A, Hinwood A, Ramalingam M, Boyce M, Heyworth J, McCafferty P, et al. Maternal exposure to metals - concentrations and predictors of exposure. Environ Res. 2013;126:111-7.

34. Gunier R, Mora AM, Smith DR, Arora M, Austin C, Eskenazi B, et al. Biomarkers of manganese exposure in pregnant women and children living in an agricultural community in California. Environ Sci Technol. 2014;48(24):14695-702.

35. Tholin K, Palm R, Hallmans G, Sandström B. Manganese status during pregnancy. Ann Ny Acad Sci. 1993;678(1):359-60.

36. Tsai M-S, Liao K-W, Chang C-H, Chien L-C, Mao IF, Tsai Y-A, et al. The critical fetal stage for maternal manganese exposure. Environ Res. 2015;137:215-21.

37. Kirchgessner M, Sherif $Y$, Schwarz F. Changes in absorption of manganese during gravidity and lactation. Ann Nutr Metab. 1981;26(2):83-9.

38. Das $K$, Chowdhury A. Metallic ion concentration during menstrual cycle in normally menstruating women. Ind J Med Sci. 1997;51(2):52.

39. Health Canada. Report on Human Biomonitoring of Environmental Chemicals in Canada: Results of the Canadian Health Measures Survey Cycle 1 (2007-2009). http://www.hc-sc.gc.ca/ewh-semt/alt_formats/hecs-sesc/pdf/ pubs/contaminants/chms-ecms/report-rapport-eng.pdf. Accessed 24 Dec 2015. 2010

40. Ohashi F, Fukui Y, Takada S, Moriguchi J, Ezaki T, Ikeda M. Reference values for cobalt, copper, manganese, and nickel in urine among women of the general population in Japan. Int Arch Occ Env Hea. 2006;80(2):117-26.

41. Goullé J-P, Mahieu L, Castermant J, Neveu N, Bonneau L, Lainé G, et al. Metal and metalloid multi-elementary ICP-MS validation in whole blood, plasma, urine and hair: Reference values. Forensic Sci Int. 2005;153(1):39-44.

42. Heitland P, Köster HD. Biomonitoring of 30 trace elements in urine of children and adults by ICP-MS. Clin Chim Acta. 2006;365(1-2):310-8.

43. Ghosh R, Rankin J, Pless-Mulloli T, Glinianaia S. Does the effect of air pollution on pregnancy outcomes differ by gender? A systematic review. Enviro Res. 2007;105(3):400-408.

44. Lin Y-Y, Leon Guo Y-L, Chen P-C, Liu J-H, Wu H-C, Hwang Y-H. Associations between petrol-station density and manganese and lead in the cord blood of newborns living in Taiwan. Environl Res. 2011;111(2):260-5.

45. Erikson KM, Dorman DC, Fitsanakis V, Lash LH, Aschner M. Alterations of oxidative stress biomarkers due to in utero and neonatal exposures of airborne manganese. Biol Trace Elem Res. 2006;111(1-3):199-215.

46. Sánchez DJ, Domingo J, Llobet JM, Keen CL. Maternal and developmental toxicity of manganese in the mouse. Toxicol Lett. 1993;69(1):45-52.

47. Palacios C. The role of nutrients in bone health, from A to Z. Crit Rev Food Sci. 2006;46(8):621-8

48. Aschner JL, Aschner M. Nutritional aspects of manganese homeostasis. Mol Aspects Med. 2005;26(4):353-62.
49. Hansen S, Spears J, Lloyd K, Whisnant C. Feeding a low manganese diet to heifers during gestation impairs fetal growth and development. J Dairy Sci. 2006;89(11):4305-11.

50. Keen C, Ensunsa J, Watson M, Baly D, Donovan S, Monaco M, et al. Nutritional aspects of manganese from experimental studies. Neurotoxicology. 1999;20(2-3):213-23.

51. Erikson KM. Manganese Dosimetry: Species Differences and Implications for Neurotoxicity. 2005

52. Smargiassi A, Mutti A. Peripheral biomarkers and exposure to manganese. Neurotoxicology. 1998;20(2-3):401-6.

53. Rodrigues EG, Kile M, Dobson C, Amarasiriwardena C, Quamruzzaman Q, Rahman M, et al. Maternal-infant biomarkers of prenatal exposure to arsenic and manganese. J Expo Sci Env Epid. 2015;25(6):639-48.

\section{Submit your next manuscript to BioMed Central and we will help you at every step:}

- We accept pre-submission inquiries

- Our selector tool helps you to find the most relevant journal

- We provide round the clock customer support

- Convenient online submission

- Thorough peer review

- Inclusion in PubMed and all major indexing services

- Maximum visibility for your research

Submit your manuscript at www.biomedcentral.com/submit
Biomed Central 